\title{
Respondiendo preguntas
}

\section{Answering questions}

\section{Leonardo Romero}

Editor Jefe, Instituto de Investigación de Ciencias Biológicas Antonio Raimondi, Facultad de Ciencias Biologicas, Universidad Nacional Mayor de San Marcos. Apartado 11-0058, Lima 11, Perú. Email: Iromeroc@unmsm.edu.pe

Con frecuencia resuelvo consultas sobre los procedimientos que se llevan a cabo en la revista, por E-mail, en conferencias, charlas, en el pasadizo. Muchas de las preguntas se repiten o son en esencia las mismas. Sin embargo, algunas preguntas son difíciles de responder para mí, generalmente la respuestas se convierten en un espiral de conceptos algunas veces aparentemente inconexos. En el presente escrito tampoco responderé a las preguntas sino que intentaré relacionarlas con el aspecto más importante dentro de una política editorial, la comunidad científica que la sustenta, una comunidad en la búsqueda de encontrar la verdad y que busca un medio para difundir sus investigaciones.

\section{Un autor: ¿Su revista es indizada? ¿En qué base de datos está? ¿Cuál es su factor de impacto?}

Muchas veces luego de la pregunta uno llega a la conclusión que existe un gran desconocimiento de lo que significa la indización. [Indización= indexación]. Para algunos la palabra indización es como el referente de un video juego o película de ciencia ficción, sabemos algunas cosas de ella, pero no todo, lo que trasciende es que esa palabra es muy importante y hay que mencionarla como una misteriosa cábala que puede darnos "un poder". En esa magia de palabras recibimos un conjuro más preciso "¡está indexada en ISI”? Entendemos que cuando nos preguntan sobre una revista indizada en "ISI" se refieren al Institute for Scientific Information, aunque también podría haber significado International Statistical Institute o el Information Sciences Institute, de hecho una forma más tangible de referirse sería Thomson ISI, la poderosa empresa dueña de las bases de datos más importantes en ciencias.

La indización en el actual imaginario de los científicos, evolucionó a partir del deseo de los bibliotecólogos de difundir las publicaciones llegadas a la biblioteca, porque "toda información que no se ve no existe”. Hoy para la mayoría de los investigadores la indización está materializada* en la Web of Science (WoS) o la ISI Web of Knowledge (WoK). Algo que sucedió en esta evolución, entre el primer momento y el actual, es el cambio de los conceptos manteniendo las mismas palabras. El cómo y el por qué lo podemos encontrar en las ideas del Dr. Eugene Garfield quien en 1955 introdujo en el mundo científico su concepto de indización y citas. El trabajo de Garfield dio vida a las citas que aparecen al final de una publicación, las utilizó para deducir la importancia de las revistas, los artículos, los temas, los investigadores, etc. Las ideas de Garfield propusieron que una colección relativamente pequeña de revistas "muy importantes” pueden concentrar casi toda la información relevante y útil para seguir haciendo ciencia, a esa colección se la empezó a denominar "la corriente principal” (main stream). ¿Y cómo Garfield llegó a esto?, con el desarrollo de un índice denominado factor de impacto, para muchos un índice perverso.
La indización implica identificar una serie de elementos en un artículo y llevarlos a una base de datos, eso significa que después de la edición la indización conlleva a una inversión extra. Una vez indizados, los artículos quedan como unas piezas que se van a engarzar en un complejo y preciso mecanismo. Son las bases de datos las que dan vida a esa información permitiéndola usar e investigar. Existen diferentes tipos de bases de datos, algunas solamente proporcionan información básica sobre la revista, otras permiten búsquedas de información en todo nivel y en coberturas increíbles.

Aunque no es imposible llegar a pertenecer a las bases de datos más importantes (léase Web of Science) requiere ciertas condiciones de producción que aseguren la calidad de la revista. Es como hacer chocolates en casa, pueden ser muy deliciosos, al inicio podemos ofrecerlos a los que pasan, si tienen acogida y la demanda se incrementa, tendremos que adoptar ciertas medidas que ayuden a la distribución, duración del producto... un buen empaque. Pero esto es rentable siempre que nuestra producción se incremente...entonces tenemos que buscar más mercado y producir más...luego ya no podremos hacerlo en casa...es muy pequeña...después necesitamos más y más condiciones para seguir creciendo. ¿Hasta dónde podemos cambiar sin modificar substancialmente su primigenia naturaleza? Una revista que ingresa a una base de datos prestigiosa tendrá mas acogida, pero para llegar a esto necesitará un salto, o algo parecido a una eclosión, romper con ciertas cosas que podíamos hacer cuando éramos pequeńos y ahora ya no es factible por razones de nuestro balance "costo/beneficio". Si una revista es formada por una comunidad, el ritmo de cambios en la política editorial será controlado por la misma comunidad. En cambio si la revista trata de formar una comunidad para sustentarse, procesos como la indización en bases de datos más exigentes podrían llevar a una erosión de la comunidad y la recepción de nuevos miembros con diferentes intereses; ¿podremos moldear ese futuro? El objetivo primigenio de la revista fue válido ¿̨será válido después de los cambios? Podemos tener motivos para cambiar, pero no necesariamente se justifican.

\section{Un amigo bien intencionado: ¿Qué necesitas para que tú revista sea ISI?}

En algunos momentos imagino la política de investigación representada por una estatua semejante a la de la justicia. Una señora (supongo porque tenemos la imagen de la mujer como no corrupta) con una balanza en una mano, donde la masa (de investigadores) determina donde se inclina, una espada en la otra mostrando su poder y autoridad (o autoritarismo), y por último una venda para no ver lo que hace.

Las políticas de investigación muchas veces están dirigidas a cubrir necesidades e intereses dispares y crean escenarios contrastantes. Es así que aunque existe cierta relación entre ser un 
buen investigador y ser un buen editor son cosas diferentes y que frecuentemente se confunden, por ese motivo instruir a un investigador en preparar una publicación es diferente a enseñar a un editor la labor de edición; los intereses de los investigadores podrían bajo ciertas circunstancia ser contrapuestos al de un editor, sino fuera así no existirían tantos fraudes científicos en publicaciones. También se confunden los conceptos en las políticas de fomento a la investigación, por un lado tenemos el fomento a la producción científica, es decir el incremento del número de publicaciones de cada investigador; por otro lado está el trabajo de una revista científica, cuya misión, además de sobrevivir es la de difundir y documentar la investigación científica de una comunidad. Podríamos decir que estos dos temas son igual de importantes, sólo que ambos deben estar bien dirigidos y no contraponerse, por ejemplo es negativo apoyar al investigador sin poner condiciones sobre la calidad de la revista en que se publica.

Las paradojas mencionadas suceden en el mundo de la ciencia, en cualquier mundo (me refiero al primero...tercer mundo). En la actualidad en que estamos imbuidos en la era global, de la información o del conocimiento, la ciencia sustentada por sociedades científicas parece perder consistencia. Sin embargo, son las sociedades científicas las que podrán mantener viva a las revistas. Para un investigador lo mejor es intercambiar ideas, lograr demostrar sus hipótesis, comunicar un hallazgo, discutir sus resultados, dentro de una comunidad en la que él sabe que los pocos que lo leerán podrán enriquecer y utilizar esa idea o información. Si es así, entonces lo primero que hay que tomar en cuenta para desarrollar una revista científica sería consolidar una comunidad que la respalde. Un grupo académico o profesional comprometido con un propósito y la revista seria su medio de comunicación y documentación.

Podemos ver en INTERNET que existe competencia entre las grandes bases de datos, además de la ISI Web of Knowledge se levanta la base de datos Scopus, en algunos años más, tal vez habrán más bases de datos o tal vez ninguna de las que conocemos hoy, muy posiblemente ni siquiera serán como las conocemos ahora. La información da poder para muchas cosas. Pero de todas maneras la información siempre será generada por los investigadores y discutida en las comunidades científicas. Si algo necesita hacer una revista será mantenerse en su propósito y buscar ser reconocida por su comunidad científica.

\section{Un administrador del instituto: ¿no será más barata la publicación por INTERNET?}

La sociedad en general y en particular el mundo académico han pasado a una dimensión en la que se cumplen los sueños de la ciencia ficción. Nos sentamos frente a una computadora, sobre un recuadro escribimos unas palabras y aparecen miles de títulos de artículos de cientos de revistas. Hace unos 30 años tomábamos una banca y caminábamos entre anaqueles llenos de revistas y libros, hojeábamos contenidos y apuntábamos en fichas bibliográficas. En esas épocas nos movíamos más.
Recibir de INTERNET toda esa información tan variada y en tan poco tiempo nos insinúa un escenario nuevo y la pregunta ¿qué trascendencia tienen las revistas? ¿Podría haber algo así como un ente que recopile toda la información? ¿Un sistema único en todo el planeta, o el país, juntar todos los trabajos, evaluarlos y publicarlos? De hecho podríamos suponer que una base de datos como Scopus o ISI Web of Knowledge son como superrevistas o metarrevistas, dependiendo qué tan maravillados estemos.

Pero podríamos argumentar que mientras más revistas más diversidad de ideas y estilos, y que al igual que la diversidad genética de una población permite que la población esté preparada para los cambios, más revistas permitirán más posibilidades de salvar las ideas e información, que podrían en otro escenario o en otro momento, simplemente ser refundidas en el olvido o perderlas materialmente.

Recuerdo penosos casos (indocumentados) en los que gran cantidad de tesis y revistas fueron destruidos por diversos motivos, todos injustificables. En la actualidad existen sistemas de repositorios digitales, administradores de contenido (CMS) que permiten organizar, documentar y dar visibilidad por INTERNET a toda aquella información que se desee. Además de ello, algunos sistemas garantizan la preservación de esos documentos (Eprint, Dspace). En un país como el Perú, la generación de una tesis es un logro importantísimo y su destrucción un crimen. En el caso mencionado me pregunto ¿Cómo una comunidad científica lo permitió? ¿Cómo sucedió? ¿Es una amenaza constante? ¿Cómo podremos enfrentarlo? Si pensamos en INTERNET para colocar la información científica debemos pensar en los beneficios que pueden brindar, nuevas y mejores estrategias de vida para las revistas, las ideas y la ciencia.

No puedo escapar a tener una política editorial, tampoco puedo escapar a las exigencias del mercado, ni a la competencia, ni a los violentos cambios producidos en los últimos tiempos. Estas preguntas, así como otras demandan acciones que a su vez cambiarán las preguntas que a su vez...nos harán caminar por un jardín de los mil senderos que se bifurcan. A pesar de ello, lo básico subyace y mantiene la superestructura: la comunidad científica. Tal vez la única respuesta a todas las preguntas sería preocuparse por la consolidación de las comunidades científicas.

*Nota: El grupo de revistas consideradas de main stream son indizadas y analizadas por el Journal Citation Reports, el cual proporciona los índices de impacto. Son estos índices los que se proponen medir objetivamente que tan consultada puede ser una revista, artículo, investigador, pais, institución, etc. En realidad son solamente estas revistas a las que se les denominaría "ISI". 